\title{
USING CONTRADICTIONS TO APPRECIATE THE HISTORY OF I.S. EDUCATION IN
}

\section{SOUTH AUSTRALIA}

\author{
Mike Metcalfe \\ School Of Management, \\ University of South Australia (City West) \\ Adelaide, SA, Australia 5001 \\ mike.metcalfe@unisa.edu.au
}

\begin{abstract}
This paper presents one person's interpretation of the history of Information Systems (IS) education in South Australia (SA). The stance used to think about the history was that of seeking the contradictions, underlying tensions, which worked over time to create the present. The paper will argue this stance, suggested to the author, that IS education in SA was influenced significantly by maintaining a "how to" view of teaching IS which failed to distinguish itself from the engineering worldview. It is suggested that a 'trade school' mentality never turned into a critical academic perspective relevant to modern business schools. After explaining the underlying tension stance this paper will use extracts from a long semi-structured interview with two seminal IS educators to support this argument.
\end{abstract}

\section{THE PROBLEM STATEMENT}

Something made IS in SA what it is today. If we look at nations with differing constitutions, cultures, and worldviews then we have to quickly accept that particular past events, people and resources had a significant effect on what is seen today. While it is important to be looking forward to how things ought to be in the future, it also seems important to occasionally reflect on the forces that shaped the present. This paper will provide an outsider's inquiry into the history of IS education in South Australia.

History is written through the eyes of the winners. It is an interpretation; who, when and where are interpreted into why. Recounting the history of IS education in SA will also be such an interpretation (Mason, 1997). It would therefore seem appropriate to identify the stance used to interpret the undisputed physical facts (Checkland, 2000). The stance selected for this paper is one with a strong association to systems thinking. It is that of trying to appreciate events as the result of underlying tensions and contradictions. In this case, the tensions that influenced the evolution of IS education in South Australia, some were global, some national and some local. 
More specifically, this paper will argue that looking at the history of IS by looking at the perceived underlying tension reveals that IS education in SA was influenced significantly by the act of trying to move IS from a computer science influence without presenting it in a manner compatible with a modern business school perspective. IS was offered within a trade school worldview, not one of academic critical inquiry. These tensions need to be explained further, but first the practice of looking at history by looking at underlying tensions needs a little justification.

\section{MAKING THE STANCE EXPLICIT}

The history of IS could be studied from a variety of stances, a mix of a few, or by contrasting different stances (Gardiner, 1959) (Bannister, 2002). Examples include taking an archaeological stance. This is perhaps the default or imagined neutral stance for many IS academics looking at the history of their discipline, one aligned with the physical science. This stance encourages looking at the history of IS in terms of its past physical attributes such as student numbers, staff numbers, publications, grant dollars, number of universities, budgets etc. It would still be necessary to explain why (theorise) IS had these physical attributes. An alternative stance might have been knowledge creation. IS could have been understood in terms of what is known, its body of knowledge, such as how to design, develop and implement a complex socio-technical system. Many other possible stances could be taken.

The stance chosen was a classic in the business domain, and one with interesting associations with systems thinking. It is that of seeking contradictions or underlying tensions, which has deep roots in European Marxism and in some streams of American Pragmatism (1997). Moreover it does not offend positivist historicism (Gardiner, 1959). Identifying inherent contradictions, paradoxes, underlying tensions or the forces behind any social event is like looking 'behind' or 'underneath' the phenomenon or event. Karl Marx used the now famous example of observing the event of a caterpillar eating. No matter how carefully you measure and count details about the caterpillar, you do not really understand it - unless you know about its life cycle (including its metamorphosis into a butterfly); in other words, unless you understand the underlying tensions of survival and evolution. Sowell (1985) argues this was Marx's own research methodology where he used it to understand inherited privilege and the control of what we today might call 'knowledge' (the means of production) which had created the dreadfully oppressive class systems in Europe in the mid $19^{\text {th }}$ Century. Engles (1964), who worked closely with Marx, saw analogies between the tension in society and the tensions in nature. The underlying tension in nature is a physical competition for survival. However, these dialectic forces can be creative.

With the contradictions stance of history, what is seen as an artefact or a phenomenon is understood to be the result of hidden forces in tension. For example, the design of a building, a vehicle, or any system is the result of various technical, organisational and personal tensions. The same is true of Christmas celebrations which can be seen to be the outcome resulting from the underlying tensions of pagan ritual, the desire for mid winter celebrations and Christian church concerns over maintaining power and economics. Contradictions between those with wealth and those without, causes the creation of a police force; contradictions between ideologies cause wars. Another example is the mobile phone which can be seen in terms of contradictions such as both giving and taking away your personal freedom, and extending while thinning-down social relationships. Phones are at least two 'faced' (Janus faced), and perhaps even three or more (Arnold, 2003).

Nielsen (1996) and Mason (1969; 1996) identified various types of contradictions that might be useful to understand social systems. Nielsen defines contradiction in terms of dialectic, "change that 
emerges from the interplay of conflict and among differences and affirmation of areas of agreement”. He argues, in a dialectic with the reader, that these change processes differ in terms of emotion; they do not have to be quarrelsome, aggressive or conflictive but they can be. Identifying these types of dialectic contradictions can form a further stance of critiquing articles.

His first 'ideas' contraction involves asking yourself who is arguing with whom over what idea. Who see the same thing differently? Is the argument likely to result in one side winning or will it encourage the development of an improved idea? For example with the commercialisation of Christmas there are concerns that product developers had the idea that traditional artefacts were merely commercial products, thus frequently rather impoverished versions are produced.

Nielsen's second contradiction he calls 'action', drawing on the 'act, reflect, act' learning loops of Schon and Argyris (1996). The contradiction is between what is said and what is done. The classic example here is an organisation plan (words) that says something is important but the budget (the action) allocates very little to that activity. In the passage above, a contradiction or a tension of this type, could be identified between the Christian meaning of Christmas as a birth and the use of Christmas trees and mid winter images.

Nielsen's third contradiction is that of 'voice' where one human group develops their understandings and actions without wanting to be informed by others. In the passage above the product developers want to make cheap commercial 'look-alikes' of traditional artefacts for profit, without asking the traditional owners/users of that artefact what they think or feel. One reason may be that the developers do not want to have to deal with the 'complaints' of the traditional users who may be a whole community. Second, there can be a feeling that the traditional community will not understand or have different priorities. As a result of 'fear of confrontation', knowledge is lost.

The last of Nielsen's contradictions that will be identified here is caused by a vying for 'resources'. Human action can easily be seen as an endless process of vying for resources with other people and species. This can be used to critique the Santa passage by commenting upon the pressure on people to make a living. In this struggle to make resources and profits flow in their direction, rather than to others, people invent popular products. The early Church could be seen as vying for the resource of people’s souls, or more cynically for people's expenditure, when offering forgiveness for sins.

\section{METHOD(OLOGY)}

The contradictions stance just discussed was use to design and interpret a semi structured 2 hour interview with two retired lecturers [MB and BW] who were employed at the only South Australian University that offers an IS degree. These two interviewees are the only people who were available that had personal experience of the emergence of IS from a computing science program. I was the interviewer $[\mathrm{MM}]$. MB had a politics undergraduate degree and an MBA, BW had an economics and accounting undergraduate degree. Both later took postgraduate courses more directly related to IS when they became available, and both worked in industry in positions which involved the installation of IT and/or IT applications before taking up lecturing positions in South Australia.

Semi structure was imposed on the interview (Gubrium, 2000) by using Neilsen's four tensions (ideas, action, voice and resources) to think about the questions asked. The interviewees agreed to this approach. Their responses are therefore being used not only to present a history of IS from a specific stance but also to evaluate that stance. 
However, given the interview was a three way semi formal discussion it was hard to be too dogmatic about sticking to discussion couched in Neilsen's contradictions terms. This was made more problematic due to it not being $100 \%$ clear which contradiction covered which issue, such as the impact of microprocessors on what was taught. While acknowledging that the discussion was initially designed around the contradictions, a semi-methodical data analysis, was also used to emerge issues from the full transcript

The transcripts were analysed using the Alexander method (1964) whereby the responses to questions are turned into a series of numbered statements. These varied from one to ten sentences in length. Next the author identified which of the statements seemed connected. For example statement 4 and 30 were deemed to have the common element of the struggle to distinguish IS from computer science.

Statement 4:

BW: ... but the driving force behind it, and Mac agrees, who was probably the real father of IS education in South Australia was a fellow by the name of Allan Spears and who retired the same year that Mac started.

\section{Statement 30:}

MB: ... the power politics were that, all through the eighties there's no doubt the computing science was always more powerful than we were, because they had their own programs, their own school and so forth. We didn't even have a minor. Frankly we were just teaching courses within accountancy, as Terry and Bernell were, and we were doing it within management. We had a head out there, Bob Northcott and even Andy Duncan, who at worst were ambivalent and at best were probably mildly supportive of us. When we became a school and a program that's when we became a threat and when the old guard was moving on and that's when I think the tensions came in...Also there was some teaching information technology in the school of communications, which was the old school of library.... The nursing school was teaching a computing subject and computer science wanted to take over that.

A matrix of all the numbered statements and connections was then drafted, which was provided as input to a socio-network software package called UCINET 6 . This presents the matrix and a graph (see figure 1: Transcript Issues Network). Note that the nodes are the statement numbers and the connecting lines deemed by the author.

This network suggests that there are three main issue clusters that emerged from the interview, some more tightly clustered than others. The amount of separation in a cluster is relevant, For example the top right cluster out from statement 66 suggest this issue was discussed fairly independently of other issues. In contrast the issue cluster around statement 6 is hard to extract from the issue cluster around statement 1 . This suggests the discussion merged the two issues. 


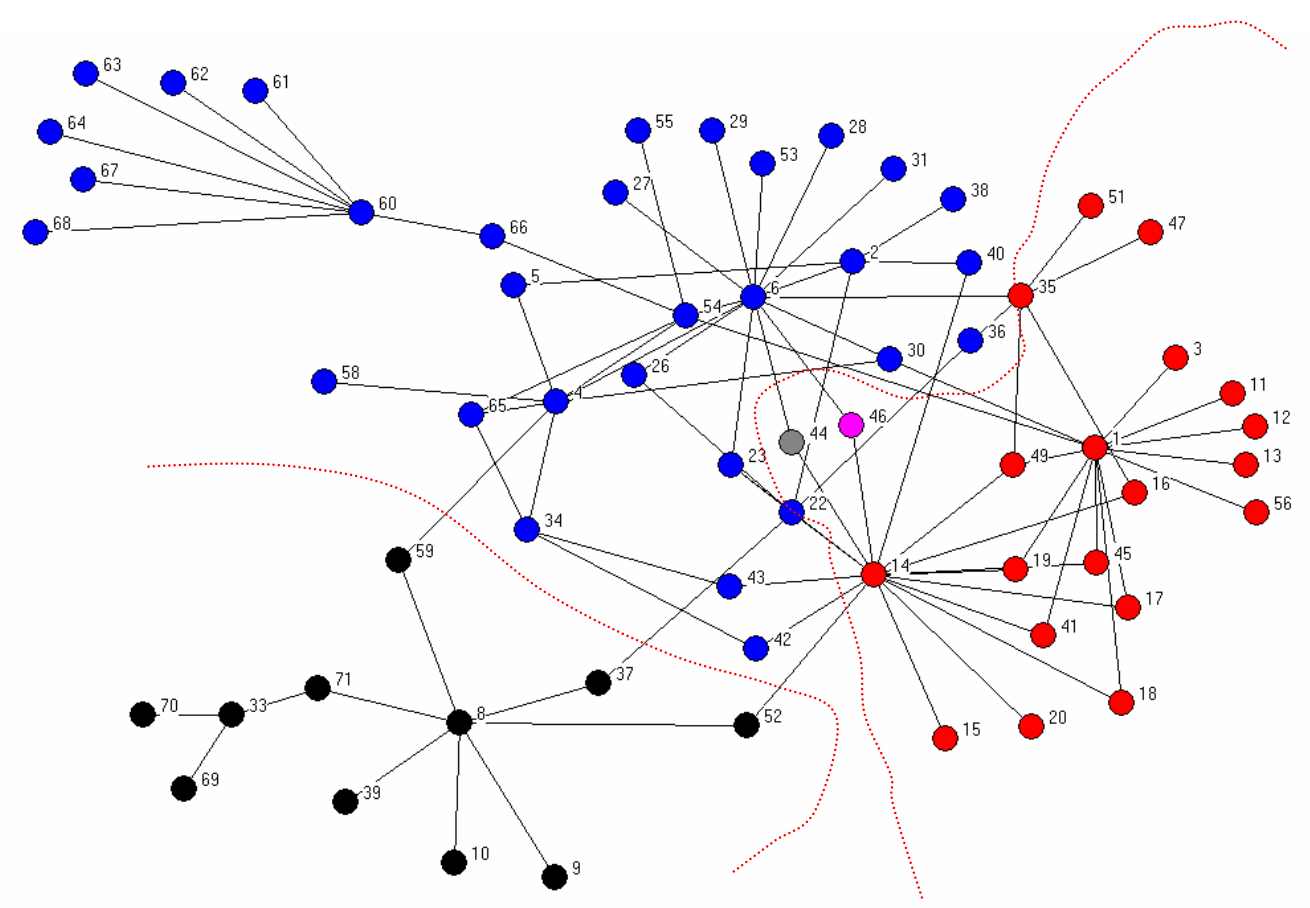

Figure 1: Transcript Issues Network

Cluster 1 - The top-left issue cluster is generally the interdepartmental struggle between IS and CS (eg 6,), trying to emphasise the vision of what IS did that was different. This would seem to be a 'resources contradiction'. Woven in with this issue was that of personalities (eg. 4, 5, 34, 65, 58, 54,26 ) which is assumed to be a 'voice contradiction'. The personality of one Head of School mentioned in one statement (54) encouraged the connecting of that statement to working conditions statements (eg. 60-68). This latter might be called an 'action contradiction' as there seemed to be some significant differences in staff workloads, qualifications and involvement in research outputs.

6: MB: Bill is saying that Allan effectively service taught systems analysis in computing science from the school of business. Then CS did the flip, took it over and it ended up being business was being service taught by computing science instead of the other way around. We had that battle for a period didn't we Bill?

5: BW: [Alan] was the driving force, initially behind teaching of systems analysis in South Australia, which was novel in the school of Computer Studies at the Levels at that time, out at Mawson Lakes. They always used to talk programming and computer hardware stuff and it was very hardware oriented, techo type course. Industry was saying, we want systems analysts. Allan, who was a very progressive sort of a guy, was also a qualified accountant. He said we really need to teach systems analysis and he got off his backside and actually devised one, he went to a couple of courses interstate himself, like a privately run course by private organisations. We're talking '74 now.

54: MB: Can I tell you a story of TR? Ok, TR, I don't know why TR left the University of ..., whatever the reason was he was actually hired by [our] School of Computing Science. 
Bill, correct me if I'm wrong, but I'm pretty sure this is right, to service teach the accountancy school because LB had either moved on or didn't want to teach their information systems course any more. So TR was service teaching accountancy. At that stage, the stirrings were coming, with BW, myself and $\mathrm{TB}$, who was basically the technology teacher at the low end of accountancy, to set up an information systems discipline. We could see in the longer term that there was strength in the accountancy and management schools getting together. We used to sort of spit at each other, but we began to realise there's probably a bigger threat, and that was computing science. Anyway, once you get old, you begin to forgive each other, their sins. We actually started talking to computer science instead of just, ignoring them. TR was the odd one, he would have to come over from computing science. I went up to Head of Accountancy, which in those days of course was what's his name, KB, and said look, is bloody stupid to have TR sitting out at computing science, we're building our own IS discipline here with management, and at that stage, $\mathrm{KB}$ was getting into bed with $\mathrm{RM}$, so there was support on their part to set up an IS discipline. Low and behold, 3 months later, TR was brought on to accountancy. ... TR had sat on the board of the School of Accountancy anyway.

66: BW: I think to be honest, it's true to say that without being rude or anything, but under TR, some people who didn't want to work didn't have to work. TR was a very easy going forgiving person and there were some people who didn't do too much at all...

63: MB: It was a different environment. It really was a different environment. That's why I moved on in 1995, because it was inevitable in a town of this size, as it would be probably anywhere, when (a) the level 2 tertiary education institution becomes a level 1 , (b) you had the CAE's and the universities, the Institute of Technology once was a CAE, but you turn a CAE into a university, and immediately all your academics are going to want to become a mini University of Adelaide. I still remember the best thing that could happen to you as an academic at a CAE was to get the calling to go the University of Adelaide. Now this is probably an outsiders viewpoint, a rather jaundiced one, but there was always that need to bid up, so it was inevitable that the Institute of Technology, and the CAE, which was a teaching institution, and very practically focused on the community it was serving, in our case, businesses, witnessed by the number of courses that Bill and I used to do, Bill especially. There's no longer any focus at all at this place, non whatsoever, except a bit of switch to research. We inherited our first 2 PhD's when we married up with this CAE and that was MR and what's his name, the big guy, big Russian fella, DS. They were 2 PhD's. I mean, they were anomalies.

Cluster 2 - The bottom-left issue cluster (eg. 8, 39, 52) is generally about 'normalising' and accrediting IS in South Australia with IS interstate $(37,71)$ and overseas (eg. 59) programs, a very South Australian preoccupation. This again may be an 'ideas contradiction' where differences need to be justified. Statement 59 can be seen to connect seeking the input of an overseas (8) personality (4).

8: MB: I came out of an MBA in Canada, supposedly the top one out of Western at the time. We had a business IT subject, I've forgotten exactly what they called it, but what we learnt at one of Canada's top MBA schools, in the second year of the MBA was nothing like what I found happening here. I came here in '76, joined in '78. What Bill was doing and what had been done under Allan Spears was certainly unique in the context as I knew it in the Canadian academic environment. They were doing things here that as 
a practicing information systems professional I could recognise as my professional area, as being IS and not business computing, which was the environment I left behind where we were learning programming and that kind of thing. There was very little systems analysis in an MBA course. It was an absolute eye opener to me in terms of what was happening in South Australia. Now whether that makes South Australia unique or Australia unique or Canada out on the edge I don't know, but my suspicion is that it was a personality buried in Adelaide that was doing things that very few people were doing anywhere else in the world.

59: BW: But one other, I would think, just thinking outside the square a little bit, but something I think influenced, MB and I considerably, was in 1982, while I was there, I called into a seminar run by the University of California in Los Angeles. I was extremely impressed by a fellow by the name of Edgar Plane, who was the bloke co-ordinating the seminar. I talked to him and he sort of said he's interested in coming to Australia. When I came back I talked to GM and the guy who ran Techsearch at the time about bringing him in running a series of, a 5-day management seminar in Australia. When he came, and I had quite a lot to do with him, and I think he was also instrumental in my thinking.

71: BW: What we were trying to do, you had to sort of battle for respectability I suppose in a way. When I went to these information systems conferences, there was a quest for establishing what the body of knowledge that represents the discipline of information systems is. There were a lot of, especially in those early conferences, a lot of people giving papers about what their perspective and what they taught and what they thought the body of knowledge that was information systems as distinct from computer science. $\mathrm{MB}$ and I, I think, were trying to get plugged in to the debate that was going on around the world in terms of what is the body of knowledge that represents information systems and we undoubtedly gave it some distinctive sort of bits and pieces of our own. We wanted our graduates to be able to go off to Sydney or New York or London or whatever, and be able to be relevant.

Cluster 3 - The right hand issue cluster is generally about the ideological struggle between providing what professionals wanted to know compared to what computer scientists wanted to program (eg 1, 11, 12, 24, ..) which is mixed up with the impact of microprocessors, spreadsheets and work processing $(15,16,17,18,20 .$.$) . This was an ideas contradiction, with the needs to advise$ accountants on how to decide their billing etc requirement so as not to be over or undersold computer power by an over enthusiastic salesperson or colleague. However, servicing accountants' needs did provide a distinct income stream, so it is also a resources contradiction.

1: BW: I graduated with an economics degree in about 1963. I was working in a job shortly thereafter in which the company was talking about computerising as everything was done manually at the time with mechanical accounting machines.

11:BW: by that stage in the piece, but nobody is telling small businesses and medium businesses how to buy a computer, what to look for in buying a new computer. Or if you've got a computer and putting a new system in, how to, how as a business person do you determine what your requirements are and those sorts of things. , if you're the managing director of some company and you've got some smart techo guy comes and starts talking about bits and bytes and codec and so on. 
12: BW: And how do you communicate [to computer engineers], how do you [professional groups] specify what your requirements are? And they [IS academics] had identified that there was a huge need for this

24: BW: Just as a matter of interest, digressing there. I remember at one stage I think MB was talking to a group about word processing and one of the blokes was from the computer society. I think he might have been from the school out at the Levels. He started thinking; oh I could write one of those. He was starting to talk about how he could write the code for the people in his company or wherever he worked, to do his own word processing programs and so on. That was their orientation.

15: BW: Well the original microprocessor/personal computer originally wasn't used to, like they are now, to do corporate processing. It was used mainly for spreadsheets and word processing and those sorts of things. We started teaching spreadsheets and so on but of course that's grown in power.

16: MB: mainly with small business people, accountants, medicine, doctors.

17: MB: I know BW disagreed with me on this but in terms of introducing spreadsheets to accountants there was only one person in Adelaide who did it and that was BW. And I still have this image of, you'd sit an accountant down and you take him through the basics of spreadsheets and somewhere around about midday they'd leap out of their chair and jump up and down and do a little jig.

18: MB: Well for a lot of small business people I certainly think it did, it put it on their desk and gave them the power to work with it.

20: BW: Basically I still spend at least half of every day of four days working spread sheets. Now, I'm writing programs associated with them.

\section{Missing Tensions?}

The analysis just summarised was an attempt to identify the underlying tensions that sculptured IS education in SA from the early 1970's to 2004. The ideas tension of lecturers being researchers now present in the discipline is seen as a late 1990's phenomenon in SA, one still resented. Indeed, the seminal characters interviewed seemed unwilling to accept that research for publication in academic journals was an effective use of their time. It almost represented a career change away from being 'doers' to one of wasting taxpayer money. MB commented that it was one reason he retired early. This reflected their understanding of their duties as educators as mainly to demonstrate to future practitioners how to manage IT; requirements calculations, systems analysis, systems design and control. They taught 'how' not 'why'. Married to this was some acknowledgement that as teachers they should make students enthusiastic about the possibilities of IT.

My suggestions that an IS discipline teach critical thinking skills in students, or to help them critique the consequences of technology beyond immediate efficiency issues, was not fully supported (Mingers, 2000). Indeed, my suggestions that IS include decision making issues or forecasting were also not taken up apparently because they were primarily concerned with the effective design and control of routine corporate operations report generation systems, such as billing reports. Given the interviewee keenness to communicate in the liberating effects of microprocessor and subsequent applications software, the discipline in SA did not develop down the 
route of designing inquiry systems. Both saw a significant moment in the development of software like word processing and spreadsheets, although they did not report that affected their mainstream teaching effort, systems analysis. Their enthusiasm for this technology change seems mainly due to how it symbolised the shift in technical power (Markus, 1987) from the engineer to the manager. It provided evidence of the distinction between IS and IT. However, issues of power were rarely discussed with students.

The educational worldview in SA seems to have been very much on supplying useful employees for industry; rather than critical thinking or knowledge creation. This was done with the well-meaning intent of wanting to assist students to be competent for international employment. There was almost no tension seen in the alternative of their role being to develop the minds of the student beyond grasping a technical and managerial skill, albeit one that would survive many of the changes in hardware and software. There was no tension in seeing technology and industry were good; their job was to ready students as suitable input into those processes. Moreover, there was no tension between their role as producing trained middle managers and their educating international thinkers or community leaders. Subjects like strategic thinking and globalisation were not seen as core.

There was also no tension expressed between their being very open to new ideas and experiences against the validity of these. There was almost no questioning of how to distinguish truth from lies, or how to inquire whether processes were unsustainable. Text book materials were taught largely as unquestioned authority, if sometimes in error. Control, measurement and error minimisation were not seen as being in tension with creativity, ethics or invention. None of which is unexpected given the 'trade school' culture of the educational organisations forced together as a University in the early 1990's. However, a lack of tension between the validity of what was taught and how that validity was determined must be a concern for any higher education.

\section{IN SUMMATION}

The 'ideas' tensions identified from the interview included the well documented ones of IS concerning itself more with managing the technology into a commercial operation compared to designing computers and programming them. This seems to have been a discipline problem rather than only being specific to SA. The alternative tension between IS and the sociology of technology seems to have not been explicit. The 'voice' tension was that computer science which had a much stronger presence in terms of academic credibility and numbers of professors. Computer science's calls for rationalisation were louder than IS's attempts to articulate even to itself its ideological differences. The 'resources' tensions were that the 1980's boom in industry and in the demand for business studies qualifications over scientific one provided students to IS over IT. However, the research earning capacity of IT schools exceeds that of IS schools. The 'actions' tensions may be seen IS teachers hiding under the blanket of the rhetoric of higher education as being the creator of knowledge, and being primarily concerned with developing the critical skill of individual students rather than merely being a provider of input to industry; a confusion of what industry wants being what the student needs.

What was taught in the classroom as IS in South Australia would seem to have focused on system analysis. The analyst was seen to be the corporation's representative in dealing with purchases from the large and powerful computer companies. BW in the interviews above said that he was under the impression that this was a fairly common vision for IS education in Australia. Those responsible for the design of local programs did so after making themselves aware of what was being taught elsewhere through conferences and email. In 1999 the Head of School at UniSA was still trying, 
somewhat unsuccessfully, to organise course sharing between Australian universities. Avgerou et al. (1999) reports that in Europe during this period there was a very diverse range of themes in IS from developing technologies per se, to the social impact of the new information and communications technologies. The author's own experience in the UK was of teaching information theory, applications appreciation and expert systems architecture in courses called Computerised Information Systems to accountants, who were originally thought of as the expert on data processing in organisations. This was in an environment of IS in the UK seeming to be obsessed with information systems development methodologies in the late 1980s and 1990s.

The emphasis on 'developing technology per se' and in applications in IS in the US during this period, rather than systems requirements, is emphasised by the assumptions in Watson et al.'s (1999) report on IS in the US. They say 'IS, perhaps more than any other field, is impacted by changes in [the technology]". This is in complete contrast to the interviewees' response. When directly asked what difference the technology made to the design of IS courses, they emphasised that IS was about assessing the information requirements of a company. What technology delivered that information was only important in the sense that it might make sought after information viable in terms of cost or speed of delivery.

In broader educational terms, this IS tertiary education appears to have been delivered under a culture of a 'trade school education', failing to clearly distinguish itself from computer science to the Universities' senior management group. Educating an IS analyst was seen as explaining how to do it, rather than developing the graduate's critical or theory based view of technology (Marks, 2001). In this culture, the management of technology meant being enthusiastic about technology which needed to be developed as rapidly as possible. Relevant research was seen as developing new, hopefully profitable, applications. It was not an education in thinking critically about technology in the business world. IS was seen, by the hard working and enthusiastic lecturers who delivered it, as existing to provide basic IS training in a profession, much like becoming an electrician or plumber. They saw the role of their IS groups as government-provided basic training to supply local industry. This training was not explicitly informed by a strategic, educational or critical worldview beyond that IT was good. 


\section{REFERENCES}

Alexander, C. (1964) Notes on the Synthesis of Form, Harvard University Press, Mass.

Argyris, C. \& Schon, D.A. (1996) Organisational Learning II, Addison Wesley, Mass.

Arnold, M. (2003) “On the Phenomenology of Technology: The 'Janus-Faces' of Mobile Phones”, Information and Organization, Vol 13, pp 231-256.

Avgerou, C., Siemer, J. et al. (1999) “The Academic Field of IS in Europe”, European Journal of Information Systems, Vol 8, pp 136-153.

Bannister, F. (2002). The Dimension of Time: Historiography in Information Systems Research. Electronic Journal of Business Research Methods 1(1): 1-10.

Checkland, P. (2000) “Soft Systems Methodology: A Thirty Year Retrospective”, Systems Research and Behavioural Science, Vol 17 No 1, S11-S58.

Engles, F. (1964) Dialectics of Nature, Progress Publishers, Moscow.

Gardiner, P. (Ed.) (1959) Theories of History, The Free Press of Glencoe, Oxford.

Gubrium, J. F. \& Holstein, J. A. (Eds.) (2000) Handbook of Interview Research: Context \& Method, Sage, Calif.

Marks, A. (2001). “A 'Polytechnism' for the British Universities: Embracing a Revised 'Soviet' Model for Academia”, Teaching in Higher Education, Vol 6 No 2, pp 275-280.

Markus, M. L. \& Bjorn-Andersen, N. (1987) "Power Over Users: Its Exercise by Professionals”, Communications of the ACM, Vol 30 No 6, pp 498-504.

Mason, R. O. (1969) “A Dialectical Approach to Strategic Planning”, Management Science, Vol 15, B-403-B-414.

Mason, R. O. (1996) “Commentary of Varieties of Dialectic Change Processes”, Journal of Management Inquiry, Vol 5 No 3, pp 293-300.

Mason, R. O., McKenney, J., et al. (1997) “Developing an Historical Tradition in MIS Research”, MIS Quarterly, (September), pp 257-278.

Mingers, J. (2000) “What is it to be Critical?” Management Learning, Vol 31 No 2, pp 219-237.

Nielsen, R. P. (1996) “Varieties of Dialectic Change Processes”, Journal of Management Inquiry, Vol 5 No 3, pp 276-293.

Sowell, T. (1985) Marxism, Unwin, London.

Watson, H. J. (1999) "Leaders Assess the Current State of the IS Academic Discipline", Communications of the Association for Information Systems, Vol 2 No 2, pp 2-27. 


\section{THE AUTHOR}

Mike Metcalfe presently works at the University of South Australia, where his main duties are $\mathrm{PhD}$ thesis adviser now in the School of Management. His own PhD was from Adelaide University, on group problem solving. He has published 6 books and over 60 lead-author refereed academic articles on problem solving using pragmatic systems thinking and argumentative inquiry, in journals that include Systems Research and Behavioral Science, IT \& People, Informal Logic and the European Journal Of Information Systems. He grew up in England, Egypt, Germany, Wales, Aden, and Singapore, moving to New Zealand in 1985. Mike has worked in the merchant navy, the British Army Parachute Regiment Reserves, the construction and food industry as a system designer, six Universities as a lecturer, and as senior policy adviser to the Deputy Premier and Treasurer of South Australia.

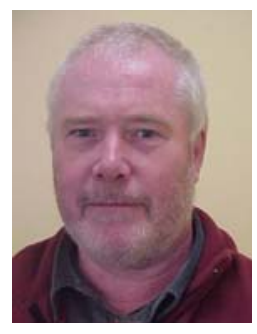

